\title{
HABERMAS: REFERENCIA, VERDAD Y MOTIVOS DEL PENSAMIENTO POSTMETAFÍSICO*
}

\author{
José Fernando García \\ Universidad Academia de Humanismo Cristiano \\ jgarcias@docentes.academia.cl
}

\begin{abstract}
Resumen / Abstract
El artículo analiza la posición del último Habermas sobre la referencia, inspirada en la obra de Putnam, mostrando que, no obstante, se aleja de ella en algunos aspectos fundamentales y que eso se explica por la necesidad de sostener un concepto de verdad independiente del contexto, central para su noción de una pragmática formal. Pero con eso se distancia de aquellos motivos de pensamiento postmetafísico que, de acuerdo a él mismo, caracterizarían a nuestra época.
\end{abstract}

Palabras Clave: verdad, referencia, relativismo conceptual, pluralismo, pensamiento postmetafísico, Habermas, Putnam.

\section{HABERMAS: REFERENCE, TRUTH AND MOTIVATIONS OF THE POSTMETAPHYSICAL THINKING}

The article discusses the last position of Habermasonreference, inspired by Putnam's work, showing that, however, its departs from it in some fundamental respects, and this is explained by the need to support a concept of context-independent truth, that is central for his notion of a formal pragmatics. But with this, he is away from the post-metaphysical thinking, whichaccording to him, would characterize our age.

KEY WORDS: truth, reference, conceptual relativism, pluralism, post-metaphysical thinking, Habermas, Putnam.

$\overline{R A}$ El proyecto filosófico de Habermas se explica en gran parte como un intento de enfrentar lo que denomina contextualismo, el que tendría como consecuencia borrar la diferencia entre el mundo intersubjetivamente compartido y el mundo objetivo, o entre el mundo y lo intramundano, y la imposibilidad resultante de comparar las imágenes del mundo lingüísticamente interpretadas desde el punto de vista de la verdad accesible a cada una de ellas. El contextualismo aparece como una posición plausible a partir del giro lingüístico o, al menos, desde una versión de éste que hipostasia la apertura de mundo del lenguaje en detrimento de su función designativa o referencial,

Una versión resumida de este artículo fue presentada al IV Congreso Iberoamericano de Filosofía, Santiago de Chile, 5 al 9 de noviembre de 2012. 
derivada, según Habermas, de las obras de Heidegger y de Wittgenstein. La verdad como des-ocultación (Heidegger) y el trasfondo en el cual se procesa la verdad y la falsedad de los enunciados (Wittgenstein), implicarían esa absolutización. "El historicismo de segundo nivel de los juegos de lenguaje y la epocal apertura del mundo son la fuente de inspiración común para una teoría de la ciencia post-empirista, una filosofía del lenguaje neo-pragmatista y para una crítica de la razón post-estructuralista" (Habermas 2002, p. 84).

La crítica de Hamann a Kant puede considerarse el origen de este énfasis holista que adquiere el giro lingüístico. Hamann localizó en el lenguaje la raíz común del entendimiento y la sensibilidad buscada por Kant y con ello confirió al lenguaje una dimensión a la vez empírica y trascendental. Es precisamente este paso el que convierte al lenguaje en una instancia que reemplaza a la consciencia en general, en la medida que ahora deben reclamarse para el lenguaje idénticas funciones constitutivas de la experiencia. Pero los lenguajes históricos que son constitutivos del mundo no tienen un equivalente a la "conciencia en general". La transformación central que este cambio de paradigma ha traído consigo parece radicar en que las "constituciones del mundo" que subyacen a los distintos lenguajes naturales deben considerarse, según la fórmula de Hamann, como algo "a priori arbitrario e indiferente pero a posteriori necesario e imprescindible" (Citado en Habermas 2002, p. 70). Pero con esto verdad y referencia se convierten en dimensiones inmanentes al lenguaje, con las consiguientes implicaciones contextualistas, dado que todo lenguaje prejuzga aquello que puede aparecer intramundanamente.

Habermas reconoce que las imágenes lingüísticas del mundo, por ser holistas, escapan en sí mismas a una valoración conforme a criterios de verdad. Admite que la elección de los criterios conforme a los cuales se juzga, en cada caso, la verdad de los enunciados depende de las categorías de la respectiva imagen del mundo (Habermas 1987, p. 89). Pero eso no impide que la propia verdad tenga que ser entendida en términos universalistas. La espontaneidad de las imágenes lingüísticas del mundo es compatible con la existencia de rasgos trascendentales universalmente extendidos que caracterizan la constitución de todas las formas socioculturales de vida, asunto que Habermas pretende demostrar por medio de una ciencia empírica reconstructiva, la pragmática formal. Desde este punto de vista, si un enunciado es verdadero, es merecedor de un asentimiento universal, cualquiera sea el lenguaje en que esté formulado. Esto daría lugar a la posibilidad de que las imágenes lingüísticas del mundo sean comparadas no solamente desde un punto de vista estético, sino también desde el punto de vista de su adecuación cognitiva.

En Verdad y justificación (publicado originalmente en 1999), Habermas vuelve a ocuparse de estos temas, retomando una vía abandonada, según nos dice, desde Conocimiento e interés (1968). Introduce allí dos argumentos nuevos en favor de un enfoque naturalista 'débil', como llama ahora lo que antes denominó 'trascendental débil', que contrapone al contextualismo: una teoría de la referencia inspirada en la obra de Hilary Putnam, y un giro pragmático de la teoría discursiva de la verdad que recoge las críticas efectuadas a la idea de ésta como justificación bajo condiciones ideales. 
Quisiera mostrar a continuación que Habermas hace un uso selectivo de la elaboración de Putnam sobre la referencia, alejándose de ella en algunos aspectos fundamentales, y que eso se explica por la necesidad de sostener un concepto de verdad independiente del contexto, que es central en su noción de una pragmática formal. Pero con eso se distancia del pensamiento postmetafísico que, de acuerdo a él mismo, caracterizaría a nuestra contemporaneidad.

Apoyándose en la obra de Putnam, Habermas arguye que son posibles procesos de aprendizaje a través de diferentes formas de vida y épocas, en cuanto hay una referencia a los mismos objetos, independientemente de sus distintas descripciones, presente en nuestras prácticas lingüísticas. El aspecto central que introduce Putnam es la desvinculación de concepto y referencia o de intensión y extensión ${ }^{1}$, y esto implica (a) que la misma intensión puede tener distinta extensión (o el mismo concepto distintas referencias), $\mathrm{y}$ (b) que distinta intensión puede tener la misma extensión (o que distintos conceptos, la misma referencia). A Habermas le interesa especialmente la implicación (b), que permite pensar la conmensurabilidad del significado a través de diferentes concepciones o culturas, evitando el contextualismo, conclusión en la cual está de acuerdo con Putnam, con distintos matices, como se verá.

Como buen filósofo de filiación analítica, a Putnam le gusta argumentar a través de experimentos mentales. Con respecto a (a) es bien conocida su historia de la Tierra y la Tierra Gemela (Putnam 1975). Estas son idénticas, excepto que en la Tierra Gemela el agua, en vez de ser $\mathrm{H}_{2} 0$, tiene otra fórmula, $\mathrm{XYZ}$, pero se comporta del mismo modo que el agua terrestre, de modo que entre el estado psicológico de un habitante de la Tierra y un habitante de la Tierra Gemela no hay diferencia. Y sin embargo, cuando un habitante de la Tierra dice 'agua' se refiere $\mathrm{H}_{2} 0$, y un habitante de la Tierra Gemela a $\mathrm{XYZ}$, independientemente de que tengan o no conocimientos de química. Putnam con esto quiere mostrar dos cosas. Primero, que el 'significado' (en el sentido de referencia) no está determinado por el estado psicológico o mental que se tenga de las expresiones lingüísticas, como ha sido la postura tradicional de los empiristas. Pero segundo, de una manera más radical, que la intensión, el concepto, la representación o la descripción, como quiera que lo llamemos, tampoco, como lo han sostenido tradicionalmente los racionalistas y logicistas ${ }^{2}$.

"En realidad, mis argumentos, al igual que los de Saul Kripke en Naming and Necessity tienen por objeto separar las cuestiones acerca de cómo se fija la referencia de esos términos de las cuestiones acerca de su contenido conceptual" (Putnam 1995, p. 71).

2 Hay dos excepciones a esto que precisa Putnam, una empirista y otra racionalista, Mill y Kant (Andrew Pessing y Sanford Golberg 1996, Introducción, nota 1) 
Cabe hacer notar que lo segundo no viene implicado por lo primero. Frege, de acuerdo a Putnam, dio el primer paso, efectuó una crítica al psicologismo, pero en la medida en que no dio el segundo, ésta termina siendo 'una tormenta en un vaso de agua', según su expresión. "Porque aún si los significados son entidades 'platónicas' y no 'mentales', desde el punto de vista de Carnap-Frege, 'captar' esas entidades es presumiblemente un estado psicológico (en el sentido estrecho). Además, solamente el estado psicológico determina a la entidad 'platónica'. Así, parecerá como una cuestión más bien convencional tomar a la entidad 'platónica' o al estado psicológico como el 'significado"' (Putnam 1975, p. 222). La conclusión es que el argumento de Frege contra el psicologismo vale solamente para la identificación de los conceptos con los estados mentales individuales, no para los conceptos en general.

Para Putnam, la referencia es fijada a través de un proceso social complejo que supone una división del trabajo lingüístico, donde hay legos y expertos, con conocimientos dispares respecto al 'significado' de los términos, disparidad que puede variar de un caso a otro y que incluye el uso de estereotipos, de marcadores sintácticos y semánticos, en fin, un conjunto de factores que no pueden ser formalizados y que Putman agrupa bajo el término 'vector de significado'. Las condiciones necesarias y suficientes para ser parte de la extensión o la referencia de un término son patrimonio de una comunidad, no de los individuos, y dentro de ella se da la división del trabajo lingüístico, la cual, como la división del trabajo a secas, supone la cooperación. Conocer el significado de una palabra significa poder usarla en la conversación o en el discurso, no conocer su referencia ni saber cómo traducirla (Putnam 1996, p. XVI). Hay, por cierto, unos mínimos 'semánticos', en cada cultura, compuestos de los estereotipos o paradigmas que todo miembro lingüísticamente competente debe conocer. A diferencia de Kripke, Putnam prefiere decir que esa referencia establecida social y cooperativamente no es rígida sino indexical (Putnam 1975, pp. 229 y ss.).

Las palabras de substancias naturales como 'agua' portan cierta similaridad al agua por aquí. El agua en otro tiempo o en otro mundo posible tiene que tener la relación 'mismo'a nuestra 'agua' para ser agua. Así, que los 'lápices orgánicos' (otra historia de Putnam) en un mundo posible sean lápices es una función de si los lápices locales son orgánicos o no. Si los lápices locales son lo que pensamos que son, no hay un mundo posible en el cual los lápices sean orgánicos. El colectivo al cual el hablante pertenece fija la extensión. "Similaridad", asume Putnam, es una noción vaga y dependiente de nuestros intereses, y cabe distinguir las cuestiones acerca de la identidad substancial en el mundo ordinario y en el mundo científico. En este último, el criterio de similaridad que establece la identidad substancial es la obediencia a las mismas leyes ${ }^{3}$ (Putnam 1992, pp. 68 y ss.).

Hay dos teorías acerca del significado de 'agua' en relación con la historia de la Tierra y la Tierra Gemela:

(1) Una sostiene que 'agua' es relativa al mundo pero constante en cuanto al significado (es decir, la palabra tiene un significado constante relativo), de manera que 'agua' significa lo mismo en $W_{1}$ y en $W_{2}$; pero ocurre que agua es $\mathrm{H}_{2} \mathrm{O}$ en $W_{1}$ y XZY en $W_{2}$. 
A partir de estos conceptos, Putnam defiende el realismo. Sostiene, por ejemplo, que la extensión del término ‘oro’ no ha cambiado significativamente en los últimos dos mil años, a pesar de que los métodos para identificar el oro se han desarrollado hasta alcanzar gran sofisticación. El anti-realista, por el contrario, no ve nuestra teoría y la de Arquímedes sobre el oro como dos descripciones aproximadamente correctas de cierta entidad independiente de las teorías. El anti-realista no tiene un concepto de verdad y de extensión (ambos están ligados) extra-teórico. Pero la ciencia misma, argumenta Putnam, usa los términos no con criterios que constituyan condiciones necesarias y suficientes de caracterización, sino como aproximación a la descripción de entidades independientes de las teorías (electricidad, por ejemplo) (Putnam 1975, pp.196-214).

En ciertos contextos puede que no sea importante (y la importancia es relativa al interés) que el agua sea pura, pero en otros contextos puede que lo sea. Lo decisivo es que los casos 'desviados' porten una relación definida con el centro del sentido. Por ejemplo, pensemos en tigres marcianos. Lucen como nuestros tigres pero tienen una química a base de silicona y no de carbono. ¿Los 'tigres' marcianos son tigres? Depende del contexto.

Putnam reconoce la deuda con Kripke y su teoría de la referencia respecto a lo nombres propios que él extiende a palabras de clases naturales y a los términos de magnitudes físicas ${ }^{4}$. Dicha teoría asume que la referencia es transmitida de hablante a hablante desde los hablantes presentes en la 'ceremonia de nombramiento', pero la transmisión no corresponde a una descripción fija. "Ninguno de los métodos de representación que conocemos tiene la propiedad de que las representaciones se refieran intrínsecamente a lo que habitualmente se refieren, sea ello lo que fuere. Todas las

(2) Otra sostiene que agua es $\mathrm{H}_{2} \mathrm{O}$ en todos los mundos (la materia llamada 'agua' en $W_{2}$ no es agua), pero 'agua' no tiene el mismo significado en $W_{1}$ y $W_{2}$.

Si lo dicho acerca de la Tierra y de la Tierra Gemela es correcto, entonces, de acuerdo con Putman, (2) es la teoría correcta. Expresa la diferencia entre ambas teorías como una diferencia de 'amplitud':

$\left(1^{\prime}\right)$ (Para todo mundo $\left.W\right)($ Para todo $x$ in $W)(x$ es agua $\equiv x$ porta igual $\mathrm{L}$ a la entidad referida como 'ésta' en $W$ )

(2') (Para todo mundo $W$ ) (Para todo $\mathrm{x}$ en $W$ ) (x es agua $\equiv$ porta igual $\mathrm{L}$ a la entidad referida como 'ésta' en el mundo real $\left.W_{p}\right)$.

$4 \quad$ "Ya he reconocido la fuerte deuda con el trabajo (no publicado) de Kripke sobre los nombres propios. Puesto que he oído principalmente informes de segunda mano de ese trabajo no intentaré describirlo aquí en detalle" (Putnam 1975, p. 203). Inicialmente, Putman da una interpretación 'minimalista' -como él mismo la llama- de la teoría kripkeana de la esencia: "Estos ejemplos sugieren que la 'esencia' que los físicos descubren está mejor pensada como una suerte de paradigma a las que otras aplicaciones del concepto ('agua' o 'temperatura') deben parecerse como una buena condición necesaria y suficiente en todo mundo posible" (Putman 1983, p. 64). Posteriormente, termina separándose de ella. "Ahora pienso que la cuestión '¿cuál es la condición necesaria y suficiente para ser agua en todo mundo posible?' no tiene sentido. Y eso significa que ahora rechazo la 'necesidad metafísica'”'(Putnam 1992, p. 70). 
representaciones que conocemos se asocian con su referencia, que es contingente y susceptible de variación a medida que cambia el mundo o la cultura" (Putnam 1995, pp. 48-49).

Respecto a la implicación (b), Putnam sostiene que el significado es, en parte, una noción normativa, en la medida en que toda interpretación depende de la caridad. Si el significado de las palabras cambiara cada vez que cambian nuestros conceptos de las cosas, la palabra 'significado' sería vacía. Cuando interpretamos tenemos que 'descontar' o hacer abstracción de algunas diferencias. De ahí que las palabras puedan mantener su significado o referencia a través de revoluciones conceptuales, como lo muestra la historia de la ciencia. "El saber distinguir entre caridad razonable y la caridad excesiva pone de manifiesto nuestras amplias facultades de entendimiento, tanto en la interpretación como en la vida real. No hay esperanzas de hallar una teoría sobre la identidad del significado o la referencia que se aplique a casos tan difíciles y que sea independiente de nuestra explicación de la 'inteligencia en general" "(Putnam 1995, p. 39).

Al mismo tiempo, Putnam defiende enfáticamente el 'relativismo conceptual', dado que aún los términos lógicos primitivos, como las nociones de objeto y existencia, no tienen un significado absoluto. Esto implica que no tiene sentido la noción de 'objetos' que existan 'independientemente' de los esquemas conceptuales, así como hablar de 'hechos' sin especificar el lenguaje usado. Pero el relativismo conceptual no es incompatible con el realismo, al menos con el realismo interno o realismo pragmático, defendido por Putnam (Putnam 1981 pp. 49-74; Torretti 2007, pp. 77-98). Hay hechos y podemos decir cuáles son, pero no podemos decirlo independientemente de alguna opción conceptual. O dicho de otra forma: el esquema conceptual restringe las posibilidades de respuesta a nuestras preguntas, pero no las determina. "Por supuesto, nuestros conceptos son culturalmente relativos, pero de esto no se desprende que la verdad o falsedad de lo que decimos usando esos conceptos esté simplemente 'determinado por la cultura"" (Putnam 1992, p. 98).

De aquí se deriva una noción pluralista de la verdad. Es posible pensar en dos esquemas conceptuales incompatibles entre sí, pero igualmente verdaderos. Por ejemplo, describir el espacio-tiempo en un lenguaje que toma los puntos como meros límites y describirlo en uno que toma los puntos como individuos y "ninguna de las dos es 'la única descripción verdadera" " (Putnam 1995, p. 175; 1994, pp. 176-177). O, para dar otro ejemplo caro a Putnam, pensemos en un mundo con tres individuos, $\mathrm{X}_{1} \mathrm{X}_{2} \mathrm{y} \mathrm{X}_{3}$. ¿Cuántos objetos hay en ese mundo? La respuesta à la Carnap sería "hay tres objetos". Pero la respuesta de un lógico polaco como Lesniewski -que piensa que por cada dos objetos particulares hay uno que es su suma (mereología)- sería que hay siete objetos: $\left(X_{1}\right)\left(X_{2}\right)\left(X_{.3}\right)+\left(X_{1}+X_{2}\right)+\left(X_{1}+X_{3}\right)+\left(X_{2}+X_{3}\right)+\left(X_{1}+X_{2}+X_{3}\right)($ Putnam 1992, p. 97).

Habermas, sin embargo, no sigue a Putnam en el relativismo conceptual ni en el pluralismo respecto a la verdad. "La teoría de la referencia de Putman explica cómo podemos mejorar la definición conceptual de un objeto manteniendo constante la referencia. Sin embargo, esta invarianza de la referencia en enunciados contrapuestos -invarianza que afecta a todas las teorías- no explica todavía cuál de estos enunciados 
es verdadero" (Habermas 2002, p. 46). La satisfacción de las condiciones de verdad de una oración empírica no puede limitarse a la satisfacción de las condiciones necesarias para efectuar con éxito la referencia. De ahí la necesidad de un concepto de verdad que no se identifique con la justificación racional, a pesar de que el acceso a las condiciones de verdad de los enunciados es epistémico, es decir, a través de razones.

Habermas pareciera sostener también, contrariamente a Putnam, que hay objetos que son independientes del lenguaje. "La práctica lingüística misma debe posibilitar, por una parte, la referencia a aquellos objetos independientes del lenguaje sobre los cuales se enuncia algo" (Habermas 2002, p. 284) ${ }^{5}$. Putnam, como hemos visto, sostiene que podemos referirnos a objetos con independencia de tal o cual descripción, pero no hay objetos con independencia de toda descripción, como pareciera entenderlo Habermas. Para Putnam que sea un objeto es relativo a algún lenguaje; mal puede haber, entonces, objetos independientes del lenguaje sobre los cuales enunciamos hechos. Esto permite comprender por qué la versión habermasiana de la concepción de Putnam sobre la referencia que, en primera instancia, da la impresión de obedecer simplemente a un descuido en el modo de expresarse, no es tal. "Hilary Putnam ha tratado la cuestión de cómo son posibles los procesos de aprendizaje más allá de las fronteras lingüísticas de distintas épocas y formas de vida especialmente desde el punto de vista de una referencia al objeto de carácter invariable" (Habermas 2002, pp. 44 y ss.). De acuerdo con este texto, la referencia, en las distintas descripciones permanece invariable o constante, lo cual, como vimos, no es fiel a la posición de Putnam.

Pero se entiende la solidaridad que hay entre ambas posturas: si los hechos tienen sus raíces en objetos que existen con independencia del lenguaje, los enunciados, en cuanto verdaderos, podrían tener una referencia invariable o constante.

\section{II}

En Verdad y justificación, Habermas concede mayor importancia a la relación entre ambos términos, aceptando el uso cautelar, preventivo o precautorio de la verdad (Habermas 2002, p. 50). La distinción cobra sentido porque afirmaciones bien justificadas que nos convencen aquí y ahora de manera irresistible pueden terminar mostrándose falsas, mientras la verdad es una propiedad que los enunciados no pueden perder. El tiempo es una limitación de tipo ontológico y dado que todos los discursos son presentes y limitados respecto al futuro, no podemos saber si las pretensiones de verdad que hoy sostenemos podrán resistir los intentos de refutación futuros. Nuestra condición finita nos limita a darnos por satisfechos con la justificación racional como

Y también: "Los hechos deben su facticidad a la circunstancia de que tienen sus raíces en un mundo de objetos (sobre los que enunciamos tales hechos) que existen con independencia de su descripción" (Habermas 2002, p. 44). 
una prueba suficiente de la verdad. No obstante, utilizamos el predicado verdad en un sentido absoluto que trasciende todas las justificaciones posibles. Esa "espina realista" impide aceptar el "idealismo lingüístico" que asimila verdad a justificación racional. Habermas cita el siguiente texto de A. Wellmer: "Siempre que sostenemos pretensiones de verdad basándonos en buenos argumentos y evidencias convincentes suponemos (....) que en el futuro no aparecerán argumentos nuevos o evidencias que pongan en cuestión nuestra pretensión de verdad" (Habermas 2002, p. 250). Frente a eso pone la pregunta: “¿Seguro que no hay explicaciones plausibles para sostener que una justificación acertada-siempre dentro de nuestro contexto- habla a favor de la verdad -independiente del contexto- del enunciado justificado?" (Habermas 2002, p. 241).

Habermas acepta las críticas al concepto epistémico de verdad como justificación en condiciones ideales, defendido en su momento por él mismo, Apel y Putnam, cuyo origen se encuentra en Pierce. La noción misma de condiciones 'ideales' -reconoce ahora- enfrenta dificultades, en cuanto supone un saber infalible que dejaría de ser humano o un lenguaje definitivo que paralizaría toda comunicación posterior, implicando la realización de un ideal cuyo cumplimiento sería el fin de la historia. Por otra parte, la definición de la verdad como justificación en condiciones ideales se distancia en exceso o no se distancia lo suficiente de la justificación en el aquí y ahora. Es decir, las presuposiciones pragmáticas ideales no pueden ser satisfechas ni siquiera aproximadamente o no son suficientes para excluir la falibilidad del consenso alcanzado discursivamente (Habermas 2002, p. 247) ${ }^{6}$.

Eso lo ha conducido a referir el concepto discursivo de justificación racional a un concepto no epistémico y pragmático de verdad, abandonando el concepto de verdad como justificación en condiciones ideales. A pesar, dice Habermas, de que no podemos evitar el nexo entre verdad y justificación -epistémicamente irrebasable- eso no implica que sea un nexo "conceptualmente indisoluble" (Habermas 2002, p. 50). El concepto de verdad supone idealizar las propiedades formales y procedimentales de la argumentación, esto es, de la justificación racional, pero la verdad misma deja de ser entendida como “justificación ideal” ¿Qué nos autoriza, entonces, a tener por verdadero un enunciado que ha sido justificado idealmente?

La práctica cotidiana se mueve dentro de un realismo que supone la existencia de un mundo objetivo único. Allí los actores dependen de certezas que se suponen incondicionalmente verdaderas. Cuando son víctimas del fracaso y del desengaño pasan de la acción al discurso, y es esta estratificación la que explica la diferencia de papeles que la verdad juega en esos distintos ámbitos. En el discurso, las interpretaciones controvertidas solamente se pueden acreditar por medio de justificaciones racionales que suponen un índice temporal y fáctico. Ahora bien, cuando los participantes en el

6 Estas críticas no alcanzan al concepto de verdad como justificación idealizada defendido por Putman. "Desde este punto de vista (el mío), entonces, la 'verdad' (justificación idealizada) es tan vaga, relativa al interés, y sensible al contexto como los somos 'nosotros'” (Putnam 1983, p. XVII). 
discurso llegan a la convicción de que conociendo todas las informaciones oportunas y las razones relevantes se han agotado las objeciones en contra de la proposición en cuestión, se acaban los motivos para permanecer en el ámbito del discurso. La desproblematización de la pretensión de verdad discutida los autoriza a volver a la actitud de la práctica cotidiana realista de trato con el mundo. "De la misma forma que, de un lado, el concepto de verdad permite la traducción de certezas de la acción quebradas en enunciados problematizados, el mantenimiento de una orientación a la verdad permite, por otro lado, la re-traducción de afirmaciones discursivamente justificadas en renovadas certezas de acción" (Habermas 2002, p. 253). La conclusión de Habermas es que la necesidad práctica de certeza en el mundo de la vida cotidiana se refleja en el plano discursivo en las connotaciones de las pretensiones de verdad, que apuntan más allá del contexto de justificación existente.

Según Habermas, este "rostro jánico" de la verdad explica la relación interna entre justificación y verdad. A la luz de las evidencias disponibles podemos plantear una pretensión de verdad que apunta más allá de aquello que está justificado en cuanto éste no es un asunto meramente epistemológico. Lo que está en cuestión es una práctica que no puede quebrarse y donde los actores tienen que referirse a un único mundo objetivo. En el mundo de la vida cotidiana, los actores dependen de certezas para llevar a cabo las acciones. No atravesamos un puente de cuya resistencia dudemos, no nos sometemos a ninguna cirugía ni comemos nada sin tener certeza sobre los conocimientos puestos en práctica. Al realismo de las prácticas cotidianas corresponde un concepto de verdad incondicionada, sin índices epistémicos. Cuando se adopta este doble punto de vista resulta claro que solamente la verdad entendida como independiente del contexto puede cumplir el papel de eliminar las perturbaciones de las certezas de la acción problematizadas. Se trata, pues, de transitar desde una justificación, como tal situada en el aquí y el ahora, a la verdad de un enunciado, que es intemporal. En una de sus formulaciones más duras, Habermas lo expresa del siguiente modo: "El objetivo de las justificaciones es encontrar una verdad que se eleve más allá de toda justificación" (Habermas 2002, p. 51) ${ }^{7}$.

Desde la reacción en contra de las interpretaciones psicologistas de Kant, primero con Lotze, pasando por los neokantianos, tanto de la Escuela de Marburgo como la de Baden, así como por Husserl, no se ha dejado de contraponer el acto de enunciar-que no puede sino estar ubicado y sometido a la contingencia del aquí y el ahora-al contenido de ese acto, que se piensa ubicado en un dominio no temporal, puramente ideal de validez. El giro lingüístico permitió incluir la crítica al psicologismo en una crítica global a la

7 Putnam, por el contrario, si bien rechaza igualmente la identificación de justificación y verdad, manteniendo la noción de verdad como idealización de la 'afirmabilidad garantizada', insiste en que ésta no es algo que pueda sobrepasar totalmente el uso. "Así, para un pragmático un debate sobre la verdad obtendrá todo su fundamento de la explicación paralela de cómo llegar a esa verdad” (Putnam 1999, p. 27). También: “...que la verdad es independiente de la justificación aquí y ahora, pero no independiente de toda posibilidad de justificación” (Putnam 1983, p. 85). 
filosofía de la consciencia. No obstante, como toda la crítica al psicologismo, postuló igualmente entidades ideales, independientes del tiempo y el espacio.

Habermas, en su crítica al contextualismo, repite el mismo gesto, separar la temporalidad del acto de justificación de la atemporalidad de aquello que es justificado. Pero, como él mismo sostiene, aunque verdad y justificación deban distinguirse, tiene que haber un nexo interno entre ellas. Se puede argumentar que son las propias justificaciones disponibles en el aquí y ahora las que nos autorizan a mantener pretensiones de verdad que van más allá del aquí y el ahora. Habermas lo pone así: "El uso 'cautelar' del predicado de verdad muestra que, con la verdad de los enunciados, vinculamos una pretensión incondicional que apunta más allá de todas las evidencias disponibles; por otra parte, las evidencias que hacemos valer en nuestro contexto de justificación tendrían que ser suficientes para autorizarnos a mantener pretensiones de verdad" (Habermas 2002, p. 238).

De modo que las pretensiones de verdad se afirman en justificaciones que tienen un índice temporal, las cuales no pueden ser reemplazadas ni dejadas atrás. Cabe preguntar entonces, ¿no se pierde el nexo interno entre justificación y verdad si ese es el caso? Pero la verdad independiente del contexto no sería ya esa justificación ubicada en el aquí y el ahora que va más allá del aquí y el ahora, sino una verdad atemporal que ha perdido todo nexo con la justificación temporal. Sin embargo, eran justamente esas justificaciones las que nos autorizaban a ir más allá de ellas y afirmar la verdad. ¿No vuelve a aparecer aquí el viejo problema de la separación entre lo real y lo ideal? ¿No tendríamos, más bien, que afirmar que la relación de lo ideal con lo real es una relación real? El mismo Habermas lo dice: "Pero estas presuposiciones contrafácticas tienen su sede en la facticidad de las prácticas cotidianas" (Habermas 2002, p. 27).

El problema es, pues, cómo se relacionan temporalidad y atemporalidad o facticidad y contra-facticidad. Habermas, por el contrario, no problematiza el asunto y parte directamente de la separación real-ideal, lo que explicaría el uso sinonímico que hace de "independencia" y "trascendencia" del contexto ${ }^{8}$.

En Habermas 2002 encontramos los siguientes pasajes: "Sólo el entrecruzamiento de estos dos roles pragmáticos distintos -que pone en juego, en plexos de acción y en discursos, aquel concepto de verdad de 'rostro jánico'- puede explicar por qué una justificación lograda en nuestro contexto habla a favor de la verdad (independiente del contexto) de la creencia justificada" (253). Y más adelante: "Pues cuando el asunto se describe en términos de teoría de la acción resulta claro que solamente si nos guiamos por la verdad entendida en un sentido independiente del contexto (esto es, por la verdad en sentido incondicional) podrá la argumentación cumplir el papel de eliminar perturbaciones de las certezas de acción que han devenido problemáticas" (245). Por otra parte, en la misma obra: "Por eso el proceso de justificación puede orientarse a una verdad que aun trascendiendo el contexto, sin embargo, es siempre operativa en la acción" (254), y también: "Pues junto con el platonismo de sus robustos conceptos de verdad y saber (referidos siempre a certezas de acción) el mundo de la vida -que en cierta medida se introduce en el discurso-ofrece el criterio a seguir para orientarse por pretensiones de verdad independientes del contexto; 
A mi modo de ver, una decisión fundamental del pensamiento de Habermas radica en la aceptación de la distinción popperiana de los tres mundos: "primero el mundo de los objetos físicos o de los estados físicos; en segundo lugar, el mundo de los estados de conciencia o de los estados mentales o, quizá, de las disposiciones comportamentales a la acción, y en tercer lugar, el mundo de los contenidos de pensamiento objetivo, especialmente de los pensamientoscientíficos y poéticos y de las obras de arte" (Popper 1982, p. 106; Habermas 1987, pp. 112 y ss.). A Popper le interesa poner en claro que no es posible interpretar el tercer mundo como expresión del segundo, ni el segundo como simple reflejo del primero. Con esto se distancia tanto de la concepción psicologista de creaciones simbólicas como de la comprensión fisicalista de la subjetividad. Por cierto, Habermas no comparte el énfasis ontológico que da Popper a la noción de mundo y se refiere más bien a la constitución de la experiencia, a más de criticarle el estrechamiento cognitivista del tercer mundo: éste incluye no solamente la verdad de los contenidos proposiciones relativos al mundo externo, sino también la rectitud, en relación con el mundo social, y la veracidad referida al mundo subjetivo, ampliación que él interpreta como una salida del logocentrismo (Habermas 1987, pp. 110 y ss.; 1989, p. 368).

Pero para Habermas, igualmente que para Popper, la validez reside en el tercer mundo, cuya característica fundamental es su autonomía respecto al segundo mundo: "El tercer mundo de Popper comprende entidades de nivel superior, que nos resultan accesibles cuando adoptamos una actitud reflexiva y que, frente al espíritu subjetivo, mantienen una cierta autonomía, porque en virtud de su referencia a la verdad constituyen una red de problemas susceptibles de investigación. En el lenguaje del neo-kantismo podríamos expresar esto diciendo que el tercer mundo goza de la autonomía de una esfera de validez" (Habermas 1987, p. 120).

Como puede leerse, Habermas habla de cierta autonomía, lo que introduce una distinción respecto a Popper. Para éste, la noción de un tercer mundo implica que sus productos tienen una historia interna, sin conexión con el segundo mundo, relativo al ámbito de lo psicológico y lo social, y cuando la tienen es un síntoma de que la historia (de la ciencia, por ejemplo) no es totalmente racional. Habermas, por su parte, asume lo que llama un "deslinde metodológico" entre una reconstrucción racional que versa sobre las relaciones internas de validez, cuyo objetivo es hacer una ordenación lógicoevolutiva, y un análisis empírico sobre los determinantes externos, sea de la racionalidad científica, de la práctico-moral, de la práctico-estética o de la estructura del mundo de la vida (Habermas 1987, p. 17). La dinámica evolutiva suministra el contenido específico en que se traducen las posibilidades circunscritas por la lógica evolutiva.

se trata, por tanto, de un criterio que trasciende la justificación, pero que siempre está ya presente en la acción" (280-281). No obstante, el siguiente texto hace la distinción entre ambos términos: "En la propia posibilidad de entendimiento lingüístico cabe leer una concepción de razón 'situada' que eleva su voz en pretensiones de validez que dependen del contexto a la vez que lo trascienden” (Habermas 1990, p. 180). 
Así, Habermas sostiene que de los sistemas culturales de interpretación o el mundo de la vida, "que reflejan el saber de fondo de los grupos sociales y que garantizan la coherencia en la diversidad de sus orientaciones de acción", cabe hacer una reconstrucción racional en cuanto constituyen procesos de aprendizaje y, por tanto, pueden ser objeto de una evaluación sistemática de acuerdo a sus condiciones internas de validez (Habermas 1987, p. 70). De este modo es posible establecer las propiedades formales que han de poseer las tradiciones culturales para constituir "un modo de vida racional" (Habermas 1987, p. 105).

Podemos establecer ahora la relación interna entre (I) y (II), esto es, entre la versión de la posición de Putnam sobre la referencia que da Habermas y su opción por una verdad no epistémica independiente del contexto.

Comencemos por preguntar: ¿son incompatibles las prácticas y el mundo objetivo que estas requieren con el relativismo conceptual y el pluralismo? El mundo único que los actores tienen que suponer para asegurar las certezas indispensables para la vida en común¿̨no puede lograrse a través de justificaciones racionales diferentes? De acuerdo al relativismo conceptual y al pluralismo es posible pensar en una referencia común que asegure ese mundo único. Esto es algo reconocido en la ciencia no solamente por filósofos como Putnam o Torretti, sino por los propios científicos. "Pero puede haber diferentes maneras en las que se puede modelar la misma situación física, cada cual empleando distintos elementos y conceptos fundamentales. Si dos de esas teorías físicas o modelos predicen exactamente los mismos eventos, no puede decirse que una sea más real que la otra; más bien somos libres para usar cualquiera que sea la más conveniente" (Hawking and Mlodinow 2010, location 66).

Obviamente, la conveniencia pragmática a la que aluden Hawkins y Mlodinow en relación con las ciencias naturales es relativa al contexto. Aunque no haya una discontinuidad absoluta, en el terreno de las ciencias sociales y las prácticas cotidianas tienen un mayor peso los juicios de valor. ¿Significa esto caer en el contextualismo, como parece ser el temor de Habermas? Que la verdad sea relativa a un esquema conceptual no significa que esté determinada por éste; la realidad pone un límite a los enunciados que son posibles de sostener al interior de cualquier esquema conceptual y, por tanto, trascienden ese esquema conceptual, aunque no sean independientes del mismo.

Que las justificaciones racionales tengan que ser referidas a un concepto de verdad trascendente (pero no independiente del contexto) que asegura el mundo único que los actores tienen que suponer no excluye el pluralismo. Lo que Putnam muestra es que, independientemente de nuestros esquemas conceptuales, hay una referencia que es común a ellos establecida socialmente. Sus argumentos sobre la división del trabajo lingüístico son convincentes; en el mundo de la vida cotidiana podemos entendernos aun cuando nuestros conceptos sean diferentes, y algo no muy distinto muestra la historia de la ciencia. 
Dado que no podemos "penetrar más allá del nexo entre verdad y justificación" (Habermas 2002, p. 50) no es posible evitar que tengamos acceso a la verdad solamente en relación con las condiciones intersubjetivas del entendimiento, relativas a un contexto. Por el contrario, la pretensión de Habermas es que la verdad entendida en sentido pragmático, que nace de la necesidad de certeza en el mundo de la vida cotidiana, requiere de una verdad sin índices temporales, independiente del contexto, que va más allá de la justificación.

La razón por la que Habermas debe evitar el pluralismo de una concepción como la de Putnam es que ésta es incompatible con la pragmática universal y la lógica evolutiva, centrales, como hemos visto, a su proyecto filosófico. La noción de una verdad plural y dependiente del contexto, el relativismo conceptual, hace imposible, en efecto, pensar en procesos sistemáticos de desarrollo, en una historia interna, puramente formal, donde quedaría alojada la validez, sin relación con una materia. El proyecto de una pragmática universal está orientado justamente a neutralizar los efectos contextuales, negando el carácter universal de la hermenéutica (Habermas 1996, pp. 277-306). Habermas evita el relativismo conceptual y el pluralismo acerca de la verdad o, para ponerlo de manera positiva, asegura la noción de una verdad, por la vía de sostener que, con independencia del lenguaje en el que estén formulados los enunciados éstos "tienen sus raíces" en objetos. Si hay objetos independientes del lenguaje están determinados los posibles enunciados verdaderos, sean cuales fueren los usos del lenguaje; estos no pueden dar lugar a verdades en plural, de acuerdo a los distintos esquemas conceptuales. O, dicho de otra manera: de acuerdo con Habermas los enunciados verdaderos agotan las verdades posibles; para el pluralismo, en cambio, establecen la verdad sin excluir otras posibles verdades.

El costo de mantener el racionalismo y el logicismo que paga Habermas es alto: la noción de una verdad independiente del contexto argumentada sobre la base de la existencia de objetos extralingüísticos, colisiona con motivos centrales de su obra, defendidos como condiciones de la filosofía hoy. Estos son cuatro: a) giro lingüístico, b) pensamiento postmetafísico, c) razón situada, d) superación del logocentrismo (Habermas 1990).

a) La idea de objetos extra-lingüísticos choca abiertamente con una de las principales consecuencias del giro lingüístico, expresada del siguiente modo por Putnam: "De hecho esta idea -que objetos y referencia surgen del discurso, en lugar de ser prioritarios a éste- está bastante generalizada en la filosofía del siglo veinte, tanto en sus variantes analíticas como 'continentales'. (Gadamer, por ejemplo, habla de objetos “emergiendo' del discurso)” (Putnam 1983, p. XVI).

b) El pensamiento postmetafísico, por su parte, supone el falibilismo, es decir, el rechazo de toda pretensión de conocimiento que suponga un acceso privilegiado a la verdad y la exigencia consiguiente de procedimientos de argumentación racionales que excluyan postulados o supuestos no expuestos a la discusión. Pero ¿cómo podríamos saber si hay objetos extralingüísticos si asumimos que todas nuestras relaciones con el mundo están mediadas por el lenguaje? 
c) A su vez, el carácter situado que nuestra época atribuye a la razón, ¿cómo puede conciliarse con la noción de una razón cuya validez es independiente del contexto y tiene una historia interna? ${ }^{9}$

d) Finalmente, esa misma razón, no ya centrada en el sujeto, sino autocentrada ¿cómo podría escapar al logocentrismo? ¿Cómo pensar que mediante una tal concepción de la razón se invierte el predominio de la teoría sobre la praxis?

Pareciera, pues, que aquella "sombra de una apariencia trascendental", ese "absoluto fluidificado y convertido en procedimiento crítico", "este residuo de metafísica" (Habermas 1990, p. 185), aquellos fantasmas que conserva el concepto de razón comunicativa, reclaman finalmente sus derechos.

\section{Referencias bibliográficas}

García, José Fernando (2012), Hacia una razón situada. Santiago: LOM, Universidad Academia de Humanismo Cristiano.

Habermas Jürgen (1987), Teoría de la acción comunicativa I. Madrid: Taurus. (1989), El discurso filosófico de la modernidad. Madrid: Taurus. (1990), Pensamiento postmetafísico. Madrid: Taurus. (1996), La lógica de las ciencias sociales. Madrid: Tecnos. (2002), Verdad y justificación. Madrid: Editorial Trotta.

Hawking Stephen and Leonard Mlodinow (2010), The Grand Design. New York: Bantam Books, Kindle eBook.

Kripke Saul (1981), Naming and Necessity. Boston: Blackwell.

Pessing Andrew y Golberg Sanford (1996), The Twin earth chronicles: twenty years of reflection on Hilary Putnam's. New York: M. E. Sharpe Inc.

Popper Karl (1982), Conocimiento objetivo. Madrid: Editorial Tecnos.

Putnam Hilary. (1975), Mind, Language and Reality. Philosophical Papers. Volume 2. New York: Cambridge University Press. Press. (1981), Reason, Truth and History. New York: Cambridge University (1983), Realism and Reason. Philosophical Papers. Volume 3. New York: Cambridge University Press. (1992), Realism with a Human Face. Harvard: Harvard University Press. (1994), Cómo renovar la filosofía. Madrid: Cátedra. (1995), Representación y realidad. Barcelona: Gedisa. 
(1999), El pragmatismo. Un debate abierto. Barcelona: Gedisa.

Torretti, Roberto, (2007), Estudios filosóficos 1986-2006. Santiago: Ediciones Universidad Diego Portales. 